\title{
Suplementação com diferentes níveis de silagem de milho para vacas de descarte de diferentes grupos genéticos submetidas ao pastejo
}

\author{
Different levels of corn silage as supplementation for cull cows from \\ different genetic groups submitted to grazing \\ Ivan Heck $^{1}$ Ivan Luiz Brondani ${ }^{2}$ Luís Fernando Glasenapp de Menezes $^{3}$ \\ Dari Celestino Alves Filho ${ }^{4}$ João Restle ${ }^{5}$ Julcemir João Ferreira ${ }^{3}$ \\ Patrícia Alessandra Meneguzzi Metz ${ }^{1}$ Roberta Farenzena ${ }^{6}$
}

\section{RESUMO}

O trabalho foi realizado objetivando-se avaliar o efeito da suplementação com silagem de milho sobre desempenho de vacas de descarte em terminação, em pastagem de aveia preta (Avena strigosa) e azevém (Lolium multiflorum). A silagem de milho utilizada foi do híbrido AG-5011, contendo 6,59\% de Proteína Bruta. Foram utilizadas 30 vacas de descarte dos grupos genéticos $3 / 4$ Charolês $(C)$ 1/4 Nelore $(N)$ ou 3/4 N 1/4 C com média de idade de 5 anos, recebendo ou não oferta de $1,25 \%$ do peso vivo $(P V)$ de silagem de milho (matéria seca) ou oferta à vontade da mesma silagem. Não houve interação entre grupo genético e oferta de suplemento. Animais que receberam silagem à vontade apresentaram maior consumo absoluto de suplemento (4,57 contra 4,34kg), desaparecendo esta diferença quando o consumo foi expresso em percentagem do peso vivo (1,07 contra 0,99\%). As vacas que receberam suplemento apresentaram maior ganho de peso médio diário $(G M D)$ em comparação às que não receberam $(0,879 \mathrm{~kg})$, independente do nível de oferta. A oferta de silagem à vontade não proporcionou maior $G M D(1,175 \mathrm{~kg})$ em relação aos que receberam $1,25 \%$ do $P V(1,214 \mathrm{~kg})$. O maior consumo de silagem proporcionou maior escore corporal final $(3,42$ pontos), sendo que as vacas que receberam $1,25 \%$ do $P V$ (3,26 pontos), não diferiram daquelas que não receberam suplemento $(3,19$ pontos $)$. As vacas $3 / 4$ C 1/4 N apresentaram maior consumo absoluto de suplemento (3,05 contra 2,89kg), maior GMD (1,196 contra 0,983kg/animal/dia) e maior escore corporal ao final do experimento (3,37 contra 3,21 pontos).

Palavras-chaves: aveia, azevém, Charolês, Nelore, volumoso

\begin{abstract}
The work was conducted to evaluate the effect of the supplementation with corn silage on the performance of finishing cull cows under oat (Avena strigosa) plus ryegrass (Lolium multiflorum) temporary grazing. The corn silage used was AG-5011 hybrid, containing $6.59 \%$ of crude protein. Thirty 3/4 Charolais (C) 1/4 Nellore (N) or 3/4 N 1/4 C culls cows with average of age of 5 years, were used, receiving or not a corn silage offer of $1.25 \%$ of live weight (dry matter) or an "ad libitum" offer. No interaction between genetic group and offered supplementation was observed. Animals that had received "ad libitum" corn silage presented greater absolute supplementation intake (4.57 against $4.34 \mathrm{~kg}$ ), disappearing this difference when the intake was expressed in percentage of the live weight (1.07 against .99\%). The cows that received supplementation presented greater average daily weight gain (GMD) in comparison to those that did not $(.879 \mathrm{~kg})$, independent of the offered level. Silage "ad libitum" offer did not provide greater GMD $(1.175 \mathrm{~kg})$ in relation to those that received $1.25 \%$ of live weight $(1.214 \mathrm{~kg})$. The higher silage intake provided greater final body condition (3.42 points), being the cows that received $1.25 \%$ of live weight (3.26 points) had no difference from those that received any supplementation (3.19 points). The 3/4 C $1 / 4 \mathrm{~N}$ cows presented greater absolute supplementation intake (3.05 versus $2.89 \mathrm{~kg})$, greater GMD (1.196 against $.983 \mathrm{~kg} /$ animal/day) and greater body condition at the end of the experiment (3.37 versus 3.21 points).
\end{abstract}

Key words: oat, ryegrass, Charolais, Nellore, roughage

${ }^{1}$ Curso de Medicina Veterinária, Universidade Federal de Santa Maria (UFSM), Santa Maria, RS, Brasil.

${ }^{2}$ Departamento de Zootecnia, UFSM, CEP: 97105-900, Santa Maria, RS, Brasil. E-mail: brondani@ccr.ufsm.br. Autor para correspondência.

${ }^{3}$ Programa de Pós - graduação em Zootecnia, UFSM. Santa Maria, RS, Brasil.

${ }^{4}$ Departamento de Zootecnia, UFSM, Santa Maria, RS, Brasil.

${ }^{5}$ Escola de Veterinária, Universidade Federal de Goiânia (UFG). Goiânia, GO, Brasil

${ }^{6}$ Curso de Zootecnia, UFSM, Santa Maria, RS, Brasil. 


\section{INTRODUÇÃO}

A produção pecuária voltada para obtenção de carne vem sofrendo sucessíveis quedas na rentabilidade, principalmente pelo aumento constante nos custos de produção e desvalorizações percentuais da carne. A competitividade da bovinocultura de corte frente a outras explorações agropecuárias depende da máxima eficiência da produção, bom planejamento e redução de custos, obtendo-se maiores lucros (SAMPAIO et al., 2001).

A pastagem cultivada de inverno é uma alternativa bastante empregada para superar o déficit forrageiro durante a estação fria no Rio Grande do Sul. As espécies forrageiras de estação fria, como a aveia preta (Avena strigosa) e o azevém (Lolium multiflorum), possuem alta digestibilidade e níveis de proteína bruta superiores às exigências das vacas em terminação (NRC, 1996). Vários autores (RESTLE et al., 2000; EL-MEMARI NETO et al., 2003) mencionam a utilização de estratégias nutricionais, como a suplementação, sendo mais rentável no inverno pela possibilidade de promover o abate dos animais na entressafra, período de melhor remuneração por kg de peso. Nesta técnica, a utilização de alimentos concentrados protéicos e energéticos são os mais utilizados. Esta escolha se baseia no manejo de fornecimento mais simplificado, que proporciona intervalos mais prolongados de permanência nos cochos, além de exigir dos produtores menor investimento em instalações e equipamentos (NUSSIO et al., 2001).

A oscilação da produção de grãos nos últimos anos, provocada por vários fatores, como o aumento dos custos de produção e a falta de valorização adequada do produto final vem onerando a alimentação de bovinos de corte (NEUMANN et al., 2002), porém a economicidade do sistema pode ser melhorada através do uso de volumosos de alto valor nutritivo e baixo custo de produção (BRONDANI et al., 2000). A silagem de milho é um volumoso em constante aumento de utilização no Brasil, sendo um importante alimento para a produção intensiva de bovinos, em função do valor nutricional que apresenta (LUPATINI \& NUNES, 1999).

A escolha do grupo genético é outra ferramenta importante na produção de bovinos de corte, e a escolha do genótipo correto pode aumentar a margem de lucro do produtor. As raças Charolês e Nelore são bastante difundidas no Brasil e muito utilizadas em cruzamentos pela complementariedade entre as duas raças, demonstrando aumento considerável no desempenho animal pelo aumento da heterose (RESTLE et al., 2001c; RESTLE et al., 2001b).
O objetivo do presente trabalho foi estudar diferentes níveis de utilização da silagem de milho como suplemento através do desempenho de vacas de descarte de diferentes grupos genéticos, mantidas em pastagem de aveia preta + azevém.

\section{MATERIAL E MÉTODOS}

O experimento foi conduzido no Setor de Bovinocultura de Corte do Departamento de Zootecnia da Universidade Federal de Santa Maria, localizado numa altitude de $95 \mathrm{~m}$, Latitude de $29^{\circ} 43$ ' Sul e Longitude $53^{\circ} 42^{\prime}$ Oeste, na Depressão Central do Rio Grande do Sul, durante o período de 15/09/2002 a 16/11/2002. Foram utilizadas 30 vacas de descarte com idade média de 5 anos e peso médio inicial de $390,7 \mathrm{~kg}$, dos grupos genéticos $3 / 4$ Charolês $1 / 4$ Nelore $e^{3 / 4}$ Nelore $1 / 4$ Charolês.

Os animas foram mantidos em pastejo durante duas horas pela manhã; após, eram retirados da pastagem para consumir o suplemento. Dez vacas receberam silagem de milho na quantidade de $1,25 \%$ do peso vivo; outras 10 vacas receberam silagem de milho à vontade, sendo que diariamente a sobra de silagem era retirada e pesada, para posterior ajuste da oferta, ao nível de $10 \%$ superior ao do consumo. As 10 vacas restantes que não receberam suplemento, voltavam para a pastagem por mais 2 horas, à tarde. A silagem de milho apresentou teor de proteína bruta (PB) de $6,59 \%$. Como o trabalho não visou à avaliação da interação entre pastagem x suplemento, todos os animais foram mantidos na mesma área de pastagem.

As pesagens dos animais e a avaliação dos escores corporais foram realizadas no início do experimento e a cada 21 dias, duração de cada período de avaliação, antecedidos de um jejum de sólidos de 12 horas. A avaliação dos escores corporais foi realizada por dois avaliadores treinados, sendo que, em todas as avaliações, foram os mesmos, em que: 1=muito magro, 2=magro, 3=médio, 4=gordo e 5=muito gordo.

A pastagem era constituída de aveia preta e azevém, implantada no dia 25/05/2002, sendo utilizada uma densidade de semeadura de $80 \mathrm{~kg}$ para aveia preta e 50kg para azevém, por hectare. Aárea de plantio havia sido previamente dessecada e o tipo de semeadura foi de plantio direto em linha. A adubação no momento do plantio foi de $350 \mathrm{~kg} /$ ha da fórmula NPK 10-18-20; a adubação nitrogenada, à base de uréia, utilizada foi de $150 \mathrm{~kg} / \mathrm{ha}$ de $\mathrm{N}$, dividida em três aplicações, nos dias 08/07; 22/08 e 17/09/02.

A estimativa da massa de forragem foi realizada pela técnica de dupla amostragem (WILM et al., 1944), sendo realizada no início do experimento e a cada 28 dias, com corte de amostras rente ao solo para

Ciência Rural, v.36, n.1, jan-fev, 2006. 
determinação de PB e da fibra em detergente neutro. $\mathrm{O}$ sistema de pastejo empregado foi a de lotação variável com uso da técnica "put and take" (MOTT \& LUCAS, 1952), objetivando manter uma massa de forragem de $1200 \mathrm{~kg} /$ ha de matéria seca (MS). Na tabela 1 , constam os resultados referentes à qualidade do pasto de acordo com os períodos de avaliação.

O delineamento experimental empregado foi o inteiramente casualizado, em um esquema fatorial $3 \times 2$ (três níveis de suplemento $\mathrm{x}$ dois grupos genéticos). Para análise estatística, os dados foram submetidos à análise de variância, teste $\mathrm{F}$ e teste de Tukey, sendo considerado significância ao nível de 5\%, pelo pacote estatístico SAS (1997).

\section{RESULTADOS E DISCUSSÃO}

Não houve interação entre tratamento e grupo genético para nenhuma das variáveis de desempenho estudadas, sendo estes efeitos analisados separadamente. Dados referentes ao consumo de silagem, pesos e escores corporais iniciais (PI e ECI) e finais (PF e ECF), ganho de peso médio diário (GMD) e ganho em EC (GEC), são apresentados na tabela 2. O consumo de matéria seca do suplemento foi maior no tratamento em que o mesmo foi fornecido à vontade. Mas, diferente do projetado inicialmente, os animais que receberam o suplemento na quantidade de $1,25 \%$ do PV, não consumiram todo, apresentando um consumo real de apenas $0,99 \%$. Assim como no tratamento que recebeu o suplemento à vontade, também no tratamento que foi fornecido $1,25 \%$ do PV, o desempenho das vacas não ficou limitado pela quantidade de suplemento fornecido. No entanto, projetou-se este estudo, fornecendo silagem de milho à vontade para compará-la quando o consumo fosse limitado em 1,25\% do PV, uma vez que em trabalho anterior (BRONDANI et al., 2003), em condições semelhantes, foi possível o consumo de silagem de milho, como suplemento, no nível de 1,20\%. RESTLE et al. (2000), suplementando vacas de descarte em pastagem de inverno, com grãos de sorgo moídos, em diferentes níveis verificaram a mesma tendência, de maior consumo com o nível fornecimento de suplemento, porém com valores inferiores de consumo total de MS de suplemento, $(2,19$ e 3,29kg/animal de MS para os níveis 0,6 e $0,9 \%$, respectivamente). Quando se analisou o consumo por $100 \mathrm{~kg}$ de $\mathrm{PV}$, não se verificou diferença significativa entre os níveis de suplementação; entretanto, o aumento do consumo real de suplemento é um parâmetro muito desejável, pois se relaciona ao incremento do ganho de peso (SANTOS et al., 2002). Os animais não apresentaram capacidade física para consumir mais do que $1,07 \%$ do peso vivo de silagem; no entanto, é importante ressaltar que o fornecimento de silagem ocorria após o período de pastejo, podendo este resultado ser diferente, caso o fornecimento do suplemento fosse ministrado pela manhã.

O peso vivo final é um parâmetro que está se tornando cada vez mais importante, uma vez que os frigoríficos exportadores vêm exigindo animais com carcaças pesadas, e segundo RESTLE et al. (2001a), o peso de abate de vacas de descarte é uma característica importante para o produtor, que recebe o valor por animal, através do peso vivo ou de carcaça. Verifica-se que o peso final dos animais, em todos os tratamentos não foi estatisticamente diferente $(\mathrm{P}>0,05)$, apesar de que as vacas que não receberam suplemento apresentarem quase $20 \mathrm{~kg}$ menos em relação às que receberam o suplemento. Esse resultado discorda, em parte, com BRONDANI et al. (2003), que observaram o mesmo peso ao final do experimento, em vacas que receberam ou não 1,2\% do PV de silagem de milho como suplemento a pastagem cultivada de inverno (485,9 contra 483,6kg, respectivamente). Esta diferença de $20 \mathrm{~kg}$ deve-se ao maior GMD $(\mathrm{P}<0,05)$ apresentado pelos animais suplementados. Observa-se ainda, na tabela 2, que o aumento na oferta de suplemento (silagem de milho à vontade) não afetou o desempenho dos animais.

STOCKDALE (1995) observou restrições à suplementação exclusiva com silagem de milho sobre o desempenho de vacas leiteiras pastejando azevém

Tabela 1 - Valores médios da massa de forragem, proteína bruta e fibra em detergente neutro da pastagem de aveia e azevém, pastejada por bovinos, de acordo com o período de avaliação do pasto

\begin{tabular}{lccc}
\hline \multirow{2}{*}{ Parâmetros } & \multicolumn{3}{c}{ Períodos } \\
\cline { 2 - 4 } & $15 / 09$ a $05 / 10$ & $06 / 10$ a 26/10 & $27 / 10$ a $16 / 11$ \\
\hline Massa de forragem, kg & 993,6 & 1075,8 & 1087,1 \\
Proteína bruta, \% & 16,9 & 19,2 & 14,0 \\
Fibra em detergente neutro, \% & 66,4 & 58,4 & 66,3 \\
\hline
\end{tabular}

Ciência Rural, v.36, n.1, jan-fev, 2006. 
perene (Lolium perenne) na Austrália. Este autor observou que as produções de leite foram reduzidas à medida que maior proporção de silagem de milho foi introduzida via suplementação. Explica também que este fato é devido à baixa disponibilidade protéica do suplemento, ocorrendo o efeito chamado de substituição, no qual o animal deixa de ingerir a pastagem de boa qualidade para consumir o suplemento. No entanto, como se pode observar, na tabela 2, apesar de haver oferta de suplemento maior não houve diferença no consumo relativo dos animais, tendo para os dois tratamentos que receberam suplemento, a mesma taxa de substituição.

Os animais que receberam maior oferta de silagem apresentaram maior escore corporal ao final do período experimental, em relação aos demais tratamentos (tabela 2). BRONDANI et al. (2003) observaram maior escore corporal final em vacas suplementadas com silagem de milho do que às suplementadas com grãos de sorgo ou às não suplementadas. Quanto ao ganho em escore corporal, os animais do tratamento de maior oferta apresentaram maior $(\mathrm{P}<0,05)$ valor do que os do tratamento testemunha, sendo que aqueles que receberam $1,25 \%$ do PV apresentaram valores intermediários. O incremento do EC é desejável pelo fato de possibilitar a comercialização antecipada dos animais, como mencionam RESTLE et al. (2001c).

$\mathrm{Na}$ tabela 3, são apresentados dados referentes ao desempenho das vacas de descarte de acordo com os grupos genéticos. As vacas $3 / 4 \mathrm{C} 1 / 4 \mathrm{~N}$ apresentaram consumo de suplemento superior
$(\mathrm{P}<0,05)$ às vacas $3 / 4 \mathrm{~N} 1 / 4 \mathrm{C}(3,05 \mathrm{~kg}$ contra $2,89 \mathrm{~kg})$. Esta diferença deve-se ao maior tamanho corporal dos animais com maior predominância Charolês, comprovado numericamente quando o consumo é expresso em percentagem do peso vivo $(0,71$ contra 0,67\%). MENEZES (2004) observou o mesmo comportamento ao terminar, em confinamento, novilhos dos mesmos grupos genéticos estudados neste trabalho. Não houve efeito $(\mathrm{P}>0,05)$ do grupo genético no peso corporal das vacas; no entanto aquelas com predominância de sangue Charolês apresentaram peso $2,79 \%$ maior que as vacas com maior predominância de sangue Nelore (466 e $453 \mathrm{~kg}$ ).

Vacas do grupo genético $3 / 4$ C $1 / 4 \quad \mathrm{~N}$ apresentaram ganho de peso médio diário superior $(1,196 \mathrm{~kg})$ que vacas $3 / 4 \mathrm{~N} 1 / 4 \mathrm{C}(0,983 \mathrm{~kg})$. Animais com predominância de sangue Charolês apresentam GMD superior aos de sangue Nelore, pelo fato da raça européia apresentar maior potencial para ganho de peso, resultante do seu maior efeito genético aditivo para esta característica (RESTLE et al., 2001a; RESTLE et al., 2001c). O peso final, maior (numericamente) nos animais $3 / 4 \mathrm{C} 1 / 4 \mathrm{~N}$, é conseqüência do maior GMD, uma vez que o peso inicial foi similar. Terminando vacas em confinamento RESTLE et al. (2001a), verificaram superioridade de $12,3 \%$ no peso final de vacas da raça Charolês, comparadas com vacas da raça Nelore. Diferença numérica no peso final de vacas $3 / 4 \mathrm{C} 1 / 4 \mathrm{~N}$ (520kg) comparado com vacas $3 / 4 \mathrm{~N}^{1 / 4} \mathrm{C}(481 \mathrm{~kg})$, foi demonstrado por RESTLE et. al (2001c), que suplementaram vacas de descarte, com grãos de sorgo em pastagem de aveia preta e azevém.

Tabela 2 - Consumo de matéria seca (CMS), CMS por 100kg de peso vivo (CMSP), peso inicial (PI) e final (PF), ganho de peso médio diário (GMD), escore corporal inicial (ECI) e final (ECF) e ganho de escore corporal (GEC) de vacas de corte com diferentes níveis de suplementação

\begin{tabular}{lccc}
\hline & \multicolumn{2}{c}{ Tratamentos } \\
\cline { 2 - 4 } Variável & P.H. + Sil. à vont.* & P.H. + Sil. 1,25\% & P.H. + P.H. \\
\hline CMS, suplemento Kg & $4,57 \mathrm{a}$ & $4,34 \mathrm{~b}$ & $0,00 \mathrm{c}$ \\
CMSP, \% & $1,07 \mathrm{a}$ & $0,99 \mathrm{a}$ & $0,00 \mathrm{~b}$ \\
PI, Kg & 391,40 & 391,70 & 389,80 \\
PF, Kg & 465,40 & 467,90 & 445,20 \\
GMD, Kg & $1,175 \mathrm{a}$ & $1,214 \mathrm{a}$ & $0,879 \mathrm{~b}$ \\
ECI, pontos & 2,81 & 2,85 & 2,86 \\
ECF, pontos & $3,42 \mathrm{a}$ & $3,26 \mathrm{~b}$ & $3,19 \mathrm{~b}$ \\
GEC, pontos & $0,20 \mathrm{a}$ & $0,14 \mathrm{ab}$ & $0,11 \mathrm{~b}$ \\
\hline
\end{tabular}

a,b Médias seguidas de letras diferentes na linha diferem $(\mathrm{P}<0,05)$ pelo teste de Tukey.

* P.H. + Sil. Ầ vont. = pastejo de 2 horas pela manhã + oferta de silagem $10 \%$ acima do consumido no dia anterior;

P.H. + Sil. $1,25 \%=$ pastejo de 2 horas pela manhã + oferta de $1,25 \%$ do peso vivo de silagem;

P.H. + P.H. = pastejo de 2 horas pela manhã + pastejo de 2 horas pela tarde.

Ciência Rural, v.36, n.1, jan-fev, 2006. 
Pode-se observar ainda, na tabela 3 , que as vacas $3 / 4 \mathrm{C} 1 / 4 \mathrm{~N}$ apresentaram maior escore corporal ao final do período experimental, reflexo também do maior GMD. Trabalhando com animais jovens, vários estudos demonstraram que a raça Nelore é mais precoce na deposição de gordura do que a Charolês (MOLETTA \& RESTLE, 1992). No entanto, em idades avanças ou peso elevado, os animais Charolês também apresentam adequada deposição de gordura na carcaça. Outra justificativa para o maior escore corporal nas vacas $3 / 4$ C $1 / 4 \mathrm{~N}$ é o maior ganho de peso apresentado por estes animais. Esses resultados concordam com MENEZES (2004), que observou que o depósito de tecido subcutâneo foi maior nos novilhos, da raça Charolês, em comparação aos da raça Nelore, abatidos aos 24 meses, justificando este comportamento pelo elevado GMD apresentado pelos animais Charolês.

\section{CONCLUSÕES}

A suplementação de vacas de descarte com silagem de milho proporciona incremento no ganho de peso médio diário e no escore corporal, antecipando a comercialização desses animais. A oferta de silagem de milho como suplemento acima de $1,25 \%$ do peso vivo não proporcionou aumento no ganho de peso, porém proporcionou elevação na condição corporal dos animais. Vacas $3 / 4 \mathrm{C} 1 / 4 \mathrm{~N}$ apresentaram ganho de peso médio diário, escore corporal e consumo absoluto de matéria seca superior em relação a vacas $3 / 4 \mathrm{~N}^{1 / 4} \mathrm{C}$.

Tabela 3 - Consumo de matéria seca (CMS), CMS por $100 \mathrm{Kg}$ de peso vivo (CMSP), peso inicial (PI) e final (PF), ganho de peso médio diário (GMD), escore corporal inicial (ECI) e final (ECF) e ganho de escore corporal (GEC) de vacas de corte de diferentes grupos genéticos

\begin{tabular}{|c|c|c|c|}
\hline \multirow{2}{*}{ Variáveis } & \multicolumn{2}{|c|}{ Grupo Genético } & \multirow{2}{*}{$\mathrm{P}>\mathrm{F}$} \\
\hline & $3 / 4 \mathrm{C}^{1} / 4 \mathrm{~N}^{*}$ & $3 / 4 \mathrm{~N}^{1 / 4} \mathrm{C}^{* *}$ & \\
\hline CMS, $\mathrm{Kg}$ & $3,05 \mathrm{a}$ & $2,89 \mathrm{~b}$ & 0,0001 \\
\hline CMSP, $\mathrm{Kg}$ & 0,71 & 0,67 & 0,5774 \\
\hline PI, Kg & 390,67 & 391,07 & 0,9860 \\
\hline $\mathrm{PF}, \mathrm{Kg}$ & 466,0 & 453,0 & 0,5878 \\
\hline GMD, $\mathrm{Kg}$ & $1,196 \mathrm{a}$ & $0,983 \mathrm{~b}$ & 0,0345 \\
\hline ECI, pontos & 2,87 & 2,81 & 0,2760 \\
\hline ECF, pontos & $3,37 \mathrm{a}$ & $3,21 \mathrm{~b}$ & 0,0008 \\
\hline GEC, pontos & 0,17 & 0,13 & 0,1813 \\
\hline
\end{tabular}

a,b Médias seguidas de letras diferentes na linha diferem $(\mathrm{P}<0,05)$ pelo teste $\mathrm{F}$.

* $3 / 4 \mathrm{C}^{1 / 4} \mathrm{~N}=3 / 4$ Charolês $1 / 4$ Nelore;

** 3/4 N 1/4 C $=3 / 4$ Nelore $1 / 4$ Charolês.

\section{AGRADECIMENTOS}

Ao Programa Institucional de Bolsas de Iniciação Científica - Conselho Nacional de Desenvolvimento Científico e Tecnológico (PIBIC - CNPq), pela concessão da bolsa ao pesquisador Heck.

À Coordenação de Aperfeiçoamento de Pessoal de Nível Superior (CAPES), pela concessão da bolsa ao pesquisador Menezes.

Ferreira e Metz.

Ao Pesquisador visitante do $\mathrm{CNPq}$, Restle.

Ao $\mathrm{CNPq}$, pela concessão da bolsa aos pesquisadores

À Pró-Reitoria de Assuntos Estudantis da Universidade Federal de Santa Maria (PRAE - UFSM), pela concessão da bolsa à Farenzena.

\section{REFERÊNCIAS}

BRONDANI, I. et al. Silagem de alta qualidade para bovinos. In: RESTLE, J. Eficiência na produção de bovinos de corte. Santa Maria: UFSM, 2000. p.185-204.

BRONDANI, I.L. et al. Desempenho de vacas em pastagem cultivada de inverno suplementadas com grão de sorgo ou silagem de milho. In: REUNIÃO ANUAL DA SOCIEDADE BRASILEIRA DE ZOOTECNIA, 40., 2003, Santa Maria. Anais... Santa Maria:SBZ, 2003. CD ROM.

EL-MEMARI NETO, A.C. et al. Suplementação de novilhos Nelore em pastejo de Brachiaria brizantha com diferentes níveis e fontes de concentrado. Revista Brasileira de Zootecnia, v.32, n.6, p.1945-1955, suplemento 2, 2003.

LUPATINI, G.C.; NUNES, S.P. Milho para produção de silagem de qualidade. In: RESTLE, J. Confinamento, pastagens e suplementação para produção de bovinos de corte. Santa Maria, UFSM, 1999. p.104-124.

MENEZES, L.F.G. Avaliação de novilhos das gerações avançadas do cruzamento rotativo Charolês - Nelore. 2004. 150p. Dissertação (Mestrado em Zootecnia) Universidade Federal de Santa Maria.

MOLETTA, J.L.; RESTLE, J. Desempenho em confinamentos de novilhos de diferentes grupos genéticos. Ciência Rural, v.22, n.2, p.227-233, 1992.

MOTT, G.O.; LUCAS, H.L. The design conduct and interpretation of grazing trials on cultivated and improved pastures. In: INTERNATIONAL GRASSLAND CONGRESS, 6., 1952, Pensylvania. Proceedings... Pensylvania: State College, 1952. p.1380-1395

NEUMANN, M. et al. Resposta econômica de terminação de novilhos em confinamento, alimentados com silagem de diferentes híbridos de sorgo (Sorghum bicolor, L. Moench). Ciência Rural, Santa Maria, v.32, n.5, p.849-854, 2002.

NATIONAL RESEARCH COUNCIL - NRC. Nutrient requeriment of beef cattle. 7.ed. Washington, DC, 1996. 232p.

NUSSIO, L.G. et al. Volumosos suplementares na produção de bovinos de corte em pastagens. In: REUNIÃO ANUAL DA SOCIEDADE BRASILEIRA DE ZOOTECNIA, 38., 2001, Piracicaba. Palestras... Piracicaba:SBZ, 2001. CD ROM. 
RESTLE, J. et al. Suplementação energética para vacas de descarte de diferentes idades em terminação em pastagem cultivada de estação fria sob pastejo horário. Revista Brasileira de Zootecnia, v.29, n.4, p.1216-1222, 2000.

RESTLE, J. et al. Efeito do grupo genético e heterose na terminação de vacas de descarte em confinamento. Revista Brasileira de Zootecnia, v.30, n.2, p.374-382, $2001 \mathrm{a}$.

RESTLE, J. et al. Características de carcaça e da carne de novilhas Charolês e 3/4 Charolês $1 / 4$ Nelore, terminadas em confinamento. Revista Brasileira de Zootecnia, v.30, n.3, suplemento 1, p.1065-1075, 2001b.

RESTLE, J. et al. Desempenho e características da carcaça de vacas de diferentes grupos genéticos em pastagem cultivada com suplementação energética. Revista Brasileira de Zootecnia, v.30, n.6, p.1813-1823, 2001c.

SAMPAIO, A.A.M. et al. Comparação de sistemas de avaliação de dietas para bovinos no modelo de produção intensiva de carne. Suplementação do pasto para vacas na estação seca. Revista Brasileira de Zootecnia, v.30, n.4, p.1287-1292, 2001 .

SANTOS, E.D.G. et al. Influência da suplementação com concentrados nas características de carcaça de bovinos F1 Limousin-Nelore, não castrados, durante a seca, em pastagem de Brachiaria decumbens. Revista Brasileira de Zootecnia, v.31, n.4, p.1823-1832, 2002.

SAS, Institute Inc. SAS'S user's guide. SAS for Windows. Cary, 1997. 1052p.

STOCKDALE, C.R. Maize silage as a supplement for pasturefed dairy cows in early and late lactation. Australian Journal of Experimental Agriculture, v.35, p.19-26, 1995.

WILM, H.G. et al. Estimating forage yield by the doublesampling methods. Journal of American Society of Agronomy, v.36, p.194-203, 1944. 